\title{
Acetylcholine Inhibits Platelet Activation
}

\author{
John A. Bennett, Sara K. Ture, Rachel A. Schmidt, Michael A. Mastrangelo, \\ Scott J. Cameron, Lara E. Terry, David I. Yule, Craig N. Morrell, and Charles J. Lowenstein \\ Aab Cardiovascular Research Institute, Department of Medicine (J.A.B., S.K.T., R.A.S., M.A.M., S.J.C., C.N.M., C.J.L.) and \\ Department of Pharmacology and Physiology (L.E.T., D.I.Y.), University of Rochester Medical Center, Rochester, New York
}

Received September 11, 2018; accepted February 12, 2019

\section{ABSTRACT}

Platelets are key mediators of thrombosis. Many agonists of platelet activation are known, but fewer endogenous inhibitors of platelets, such as prostacyclin and nitric oxide (NO), have been identified. Acetylcholinesterase inhibitors, such as donepezil, can cause bleeding in patients, but the underlying mechanisms are not well understood. We hypothesized that acetylcholine is an endogenous inhibitor of platelets. We measured the effect of acetylcholine or analogs of acetylcholine on human platelet activation ex vivo. Acetylcholine and analogs of acetylcholine inhibited platelet activation, as measured by
P-selectin translocation and glycoprotein Ilb Illa conformational changes. Conversely, we found that antagonists of the acetylcholine receptor, such as pancuronium, enhance platelet activation. Furthermore, drugs inhibiting acetylcholinesterase, such as donepezil, also inhibit platelet activation, suggesting that platelets release acetylcholine. We found that NO mediates acetylcholine inhibition of platelets. Our data suggest that acetylcholine is an endogenous inhibitor of platelet activation. The cholinergic system may be a novel target for antithrombotic therapies.

\section{Introduction}

Platelet activation is crucial for hemostasis and thrombosis (Ho-Tin-Noe et al., 2011; Stalker et al., 2014; Joshi and Whiteheart, 2017). A variety of agonists activate platelets in vivo, including thrombin, collagen, and ADP (Hechler et al., 1998; Boeynaems et al., 2005; Coughlin, 2005; Ghoshal and Bhattacharyya, 2014; Hisada et al., 2015). An equally important aspect of platelet biology is inhibition of activation, limiting excess thrombosis, which can otherwise lead to stroke or pulmonary embolism. Endogenous platelet inhibitors include factors released from endothelial cells, such as nitric oxide (NO) and prostacyclin (Moncada et al., 1977; Radomski et al., 1987b; Freedman et al., 1999; Jin et al., 2005).

Studies of adverse bleeding reactions to commonly used drugs can reveal novel inhibitors of platelet function (Holly and Parise, 2011). For example, a few case reports have suggested that acetylcholinesterase (AChE) inhibitors are associated with bleeding (Gareri et al., 2005; Cholongitas et al., 2006). Several clinical trials have examined the safety of donepezil, and one of these trials showed that donepezil increases the risk of bruising (Rogers et al., 1998;

This work supported by the National Institutes of Health [Grants R01 HL134894 and R61 HL141791 and 5T32 HL007937, R01 HL124018, K08 HL128856, R01 DE014756, and R01 DE019245] and the American Heart Association [Grant 19POST34381003].

An earlier version of this paper appears in bioR Xiv under the doi 10.1101/ 324319 .

https://doi.org/10.1124/jpet.118.253583.
Tariot et al., 2001). A meta-analysis of clinical trials of AChE inhibitors shows that these drugs increase the risk of bruising by 1.5 -fold compared with placebo, although this increased risk is not significant (Birks, 2006). These isolated clinical studies suggest that acetylcholine may be an endogenous inhibitor of platelet activation. For these reasons, we chose to examine the effect of acetylcholine signaling on platelet activation.

Prior work from other laboratories suggests that acetylcholine receptors $(\mathrm{AChRs})$ are involved in platelet function. Human platelets express subunits of the AChR (Schedel et al., 2011). Artificial agonists of AChR stimulate calcium flux across human platelet membranes (Schedel et al., 2011). Certain agonists of AChR increase human platelet activation as measured by glycoprotein IIb IIIa (GPIIbIIIa) conformational changes and by aggregation (Schedel et al., 2011). Finally, platelets from mice lacking AChR subunit Chrna7 have increased activation when stimulated by ADP (Kooijman et al., 2015). These important experimental studies suggest that acetylcholine signaling plays a role in inhibiting platelets both in vitro and in vivo.

Gaps remain in our collective knowledge pertaining to the effect of acetylcholine on platelets. The effect of acetylcholine on platelets stimulated with endogenous agonists other than ADP is not yet completely known. The effect of acetylcholine on platelet degranulation is not fully understood. The effect of endogenous acetylcholine signaling on hemostasis and thrombosis is not well defined. The expression of genes involved in acetylcholine signaling in human

ABBREVIATIONS: AChE, acetylcholinesterase; AChR, acetylcholine receptors; BAPTA, 1,2-bis(o-aminophenoxy)ethane-N,N,N',N'-tetraacetic acid; CHRNA7, cholinergic receptor neuronal nicotinic $\alpha$ polypeptide 7; FITC, fluorescein isothiocyanate; GPIIbllIA, glycoprotein IIb IIla; L-NAME, L-nitroarginine methyl ester; NO, nitric oxide; NOS3, nitric oxide synthase isoform 3; P2Y12, purinergic receptor P2Y; TRAP, thrombin receptor activating peptide 6 . 
platelets is not fully described, and the mechanisms through which clinical drugs targeting acetylcholine affect bleeding in humans has not yet been explored. Determining the role that acetylcholine signaling plays in inhibition of platelet function may help clinicians avoid the toxicity of drugs that target the parasympathetic nervous system and may help us uncover new pathways that inhibit platelet function.

\section{Materials and Methods}

Human Platelet Collection. Human blood collection was performed as previously described using protocols approved by the Institutional Review Board at the University of Rochester Medical Center (IRB Protocol RSRB00028659) (Cameron et al., 2015). Normal healthy blood donors were recruited. Subjects were excluded if they had used aspirin or any nonsteroidal anti-inflammatory agent within 10 days before the blood draw. Blood was collected by venipuncture into sodium citrate anticoagulant tubes. Whole blood was centrifuged at $180 \mathrm{~g}$ for 15 minutes to isolate the top layer of platelet-rich plasma, which was diluted 1:20 in room-temperature Tyrode's buffer (134 mM NaCl, $2.9 \mathrm{mM} \mathrm{KCl,} 12 \mathrm{mM}$ NaHCO3, $0.34 \mathrm{mM}$ Na2HPO4, $20 \mathrm{mM}$ HEPES, pH 7.0, $5 \mathrm{mM}$ glucose, 0.35\% bovine serum albumin) and dispensed in $100-\mu l$ volumes for treatment with various drugs.

Platelet Drug Treatment. Human platelets were suspended in Tyrode's buffer and placed into microcentrifuge tubes. Drugs were added, and the platelets were incubated for 15 minutes at room temperature. To some samples, L-nitroarginine methyl ester (L-NAME) was added first and incubated for 15 minutes; then carbachol (Sigma-Aldrich, St. Louis, MO) or acetylcholine (SigmaAldrich) was incubated for 15 minutes, and thrombin receptor activating peptide 6 (TRAP) (Tocris Bioscience, Oxfordshire, UK) or thrombin (Cayman Chemical Company, Ann Arbor, MI) was incubated for 15 minutes. Platelets were first treated for 15 minutes with 1,2-bis(o-aminophenoxy)ethane-N,N,N', $\mathrm{N}^{\prime}$-tetraacetic acid (BAPTA) and trifluoperazine (Sigma-Aldritch) for some experiments. For experiments involving cholinesterase inhibition, platelets were pretreated with donepezil for 15 minutes before stimulation. For experiments with $\mathrm{nAChR} \alpha 7$-selective agonist PNU-282987, platelets were pretreated for 15 minutes with PNU before stimulation. For calcium flux experiments with Fura-2 AM, platelet-rich plasma was loaded with Fura-2 AM at $5 \mu \mathrm{M}$ for 1 hour at $37^{\circ} \mathrm{C}$ and then further prepared as described to yield platelets loaded with Fura-2. HEK293 cells were also loaded as a positive control. Cells were analyzed on a Flexstation 3 (Molecular Devices, San Jose, CA) for the 340/380 Fura-2 AM ratio.

Detection of Platelet Activation by Flow Cytometry. Phycoerytherin-labeled antibody to CD62P (P-selectin) (Becton Dickinson, San Jose, CA) at a dilution of 1:100 was added to platelets after stimulation or drug treatment of 30 minutes. Platelets were then fixed in $1 \%$ formalin. Surface P-selectin was measured by flow cytometry (LSRII; Becton Dickinson). To detect conformational changes in GPIIbIIIa, fluorescein isothiocyanate (FITC)-fibrinogen (Abcam) was added for 30 minutes, and platelets were analyzed by flow cytometry. We have previously used these techniques to measure platelet activation (Zhu et al., 2014).

Quantification of cGMP Levels by Enzyme-Linked Immunosorbent Assay. Platelets were treated and stimulated as described. The reactions were stopped, and cells were lysed by the addition of $\mathrm{HCl}$ to a final concentration of $0.1 \mathrm{M}$. Samples were cleared by centrifugation $(14,000 \mathrm{rpm})$ for 20 minutes. Samples were then analyzed for cGMP content using a commercially available enzymelinked immunosorbent assay (Cayman Chemical Company).

Statistical Analyses. Data were analyzed by two-tailed Student's $t$ test for comparison of two groups and by Bonferroni corrected two-way analysis of variance to compare means of three or more groups. Statistical significance was defined as $P<0.05$.

Study Approval. Human blood collection was performed using protocols approved by the Institutional Review Board at the University of Rochester Medical Center.

\section{Results}

Acetylcholine Receptors Regulate Platelet Activation. Since patients taking acetylcholine inhibitors have an increased risk of bleeding, we hypothesized that increased acetylcholine signaling directly inhibits platelet activation. To test this hypothesis, we first analyzed the effect of carbachol, an analog of acetylcholine, on platelet activation. We treated human platelets with increasing concentrations of carbachol and then stimulated the platelets with the thrombin receptor agonist thrombin receptor activating peptide 6 (TRAP). Carbachol inhibits activation of human platelets in a dose-dependent manner (Fig. 1A). We next explored the effect of acetylcholine on platelet activation. Acetylcholine inhibits TRAP activation of human platelets in a dose-responsive manner by $>25 \%$ of maximal stimulation (Fig. 1B), and acetylcholine inhibits platelet activation over a range of TRAP doses (Fig. 1C).

We tested the effect of acetylcholine signaling on platelets stimulated with different agonists, including TRAP, which activates the thrombin receptor protease activated receptor 1 ; $\mathrm{ADP}$, which activates the ADP receptor purinergic receptor P2Y (P2Y12); U44619, which activates the thromboxane receptor TP; and convulxin, which activates the collagen receptor glycoprotein VI. Carbachol inhibits platelet activation by other agonists (Fig. 1, D-F).

The preceding data show that acetylcholine inhibits $\alpha$-granule release. Next, we tested the effect of acetylcholine signaling on other aspects of platelet activation, namely, dense granule secretion and GPIIbIIIa conformational changes. We found that the acetylcholine analog carbachol decreases dense granule exocytosis measured by release of ATP (Fig. 1G) and inhibits GPIIbIIIa activation measured by FITC-fibrinogen binding (Fig. 1H). Furthermore, endogenous acetylcholine has the same effect (as shown when the acetylcholine esterase inhibitor pyridostigmine is added) (Fig. 1G).

We also tested the effect of the nicotinic receptor agonist PNU282987 on platelet activation. We found that PNU inhibits thrombin-induced platelet exposure of P-selectin (Fig. 1I) and GPIIbIIIA activation (Fig. 1J).

Taken together, these data suggest that stimulation of the acetylcholine receptor inhibits platelet activation as measured by three separate functions: $\alpha$-granule release, dense granule release, and GPIIbIIIa activation.

Endogenous Acetylcholine Inhibits Platelet Activation. Whereas acetylcholine signaling inhibits platelet activation, the potential source of acetylcholine in vivo remains unclear. We hypothesized that platelets release acetylcholine, which inhibits platelet activation in an autocrine or paracrine manner. We treated platelets with the AChE inhibitor pyridostigmine bromide before activation and observed that inhibition of $\mathrm{AChE}$ decreases platelet activation (Fig. 2A), consistent with the idea that pyridostigmine bromide inhibits AChE, increasing the amount of acetylcholine released by platelets that is available to signal through the acetylcholine receptor. We then confirmed that pancuronium bromide, which antagonizes the acetylcholine receptor, enhances platelet 


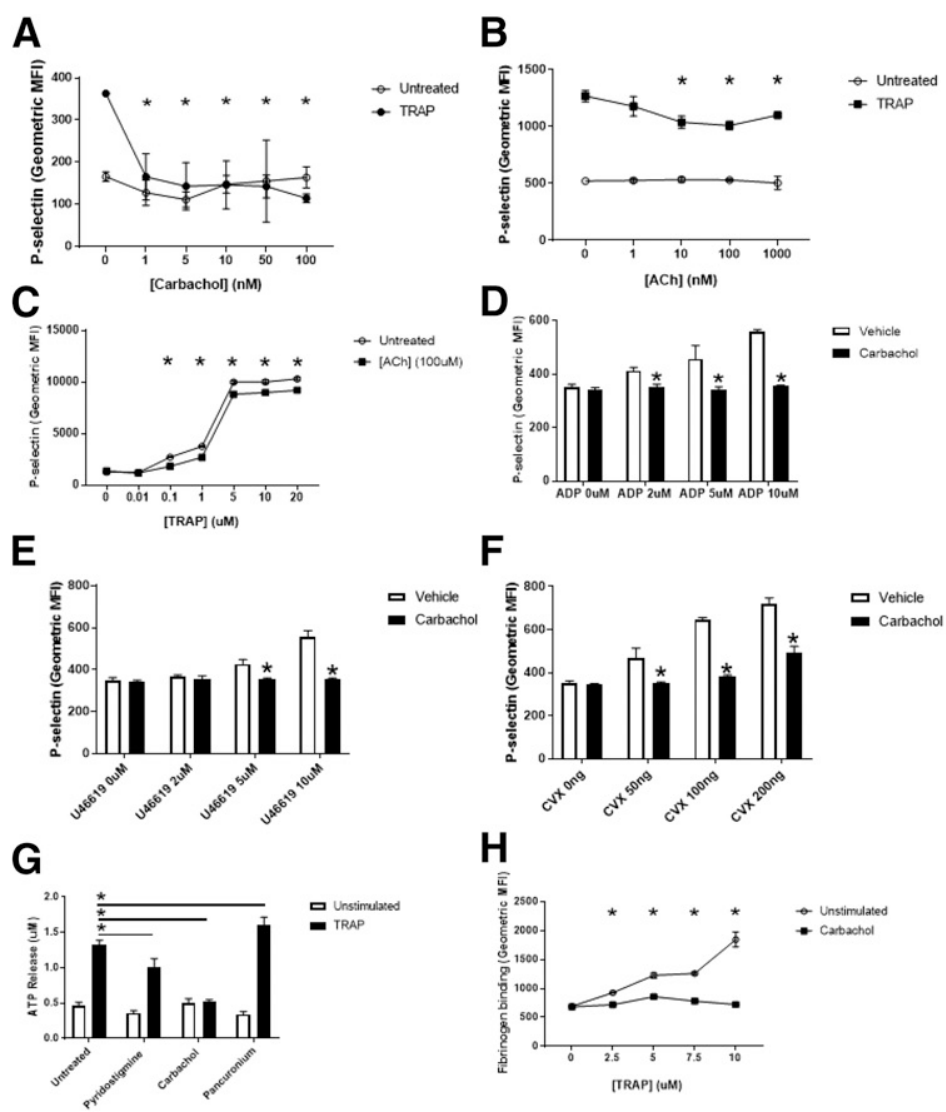

Fig. 1. Acetylcholine receptors regulate platelet activation. (A) Carbachol inhibits platelet activation. Human platelets were isolated and treated with phosphate-buffered saline or carbachol, stimulated with PBS or $10 \mu \mathrm{M}$ TRAP, and analyzed for surface expression of P-selectin using flow cytometry. ( $n=4 \pm$ S.D., ${ }^{*} P<0.05$ for TRAP vs. TRAP + carbachol). (B) Acetylcholine inhibits platelet activation. Human platelets were treated with PBS or ACh, stimulated with PBS or $10 \mu \mathrm{M}$ TRAP, and analyzed as already described. $(n=4 \pm$ S.D., $* P<0.05$ for TRAP vs. TRAP + ACh). (C) Carbachol inhibits platelet activation over a range of TRAP doses. Platelets were stimulated with varying concentrations of TRAP and analyzed for surface expression of P-selectin as desccribed $(n=4 \pm$ S.D., $* P<0.05$ for the indicated concentration of TRAP vs. TRAP + carbachol). (D) Carbachol inhibits platelet activation by ADP. (E) Carbachol inhibits platelet activation by U46619. (F) Carbachol inhibits platelet activation by convulxin. For (D-G), isolated human platelets were treated with PBS or $10 \mathrm{nM}$ carbachol, then stimulated with various agonists, and analyzed via flow cytometry $(n=4 \pm$ S.D., $* P<0.05$ for agonist vs. agonist + carbachol). (G) Carbachol inhibits platelet-dense granule release. Platelets were isolated and treated with $10 \mathrm{nM}$ carbachol, $100 \mu \mathrm{M}$ pyridostigmine bromide or $100 \mathrm{nM}$ pancuronium bromide, and then stimulated with PBS or TRAP and analyzed for surface expression of P-selectin ( $n=4 \pm$ S.D. $* P<0.05$ for TRAP vs. TRAP and indicated compound). (H) Carbachol inhibits GPIIbIIIa activation as measured by FITC-fibrinogen binding to platelets. Platelets were isolated and treated with $10 \mathrm{nM}$ carbachol and then stimulated with the indicated concentrations of TRAP and analyzed for surface expression of P-selectin $\left(n=4 \pm\right.$ S.D., ${ }^{*} P<0.05$ for TRAP vs. TRAP + carbachol). (I) Treatment with the nAChR $\alpha 7$-selective agonist PNU-282987 inhibits P-selectin exposure. Platelets were treated with PNU-282987 at the indicated concentrations, then stimulated with TRAP6, and analyzed for surface expression of p-selectin $(* P<0.05$ for TRAP6 + vehicle vs. TRAP6 + indicated concentration of PNU). (J) PNU inhibits GPIIbIIIa activation. Platelets were treated with PNU-282987 at the indicated concentrations, then stimulated with TRAP6, and analyzed for activation of GPIIbIIIa as described ( $* P<0.05$ for TRAP6 + vehicle vs. TRAP6 + indicated concentration of PNU).

activation (Fig. 2B). We tested the effect of these compounds on platelet GPIIbIIIa activation using FITC-fibrinogen and observed that agonism of acetylcholine receptors inhibits, and antagonism of acetylcholine receptors enhances, binding (Fig. 2C).

Patients who take donepezil may have an increased risk of bleeding (Rogers et al., 1998; Tariot et al., 2001; Cholongitas et al., 2006). Since donepezil is an acetylcholinesterase inhibitor, we hypothesized that donepezil inhibits platelet activation. To test this hypothesis, we treated platelets with donepezil hydrochloride and then stimulated them with TRAP. Donepezil inhibited platelet activation (Fig. 2D). These data are consistent with the hypothesis that endogenous acetylcholine released from platelets inhibits platelet activation.

Collectively, these data suggest platelets can release acetylcholine, which limits activation, and endogenous AChE blunts the extent of endogenous acetylcholine signaling.
Nitric Oxide Mediates Acetylcholine Inhibition of Platelet Activation. We next explored the mechanism through which acetylcholine signaling inhibits platelet activation. AChRs increase the synthesis of $\mathrm{NO}$ in endothelial cells (Zuccolo et al., 2017). Platelets express nitric oxide synthase isoform 3 (NOS3) (Sase and Michel, 1995). We proposed that nitric oxide mediates acetylcholine inhibition of platelets. To test our idea, we treated human platelets with an inhibitor of nitric oxide synthase, L-nitroarginine methyl ester (L-NAME), and then treated with carbachol and stimulated with TRAP. We observed that carbachol inhibits platelets, but NOS inhibition blocks the effects of carbachol (Fig. 3A). To confirm that acetylcholine signaling triggers $\mathrm{NO}$ synthesis in platelets, we measured carbachol stimulation of cGMP, a messenger downstream of NO. Carbachol increases cGMP levels in human platelets, and the effect of carbachol is blocked by the NOS inhibitor L-NAME (Fig. 3B). The inhibitory effect of NO was further tested with a range of L-NAME doses. We 

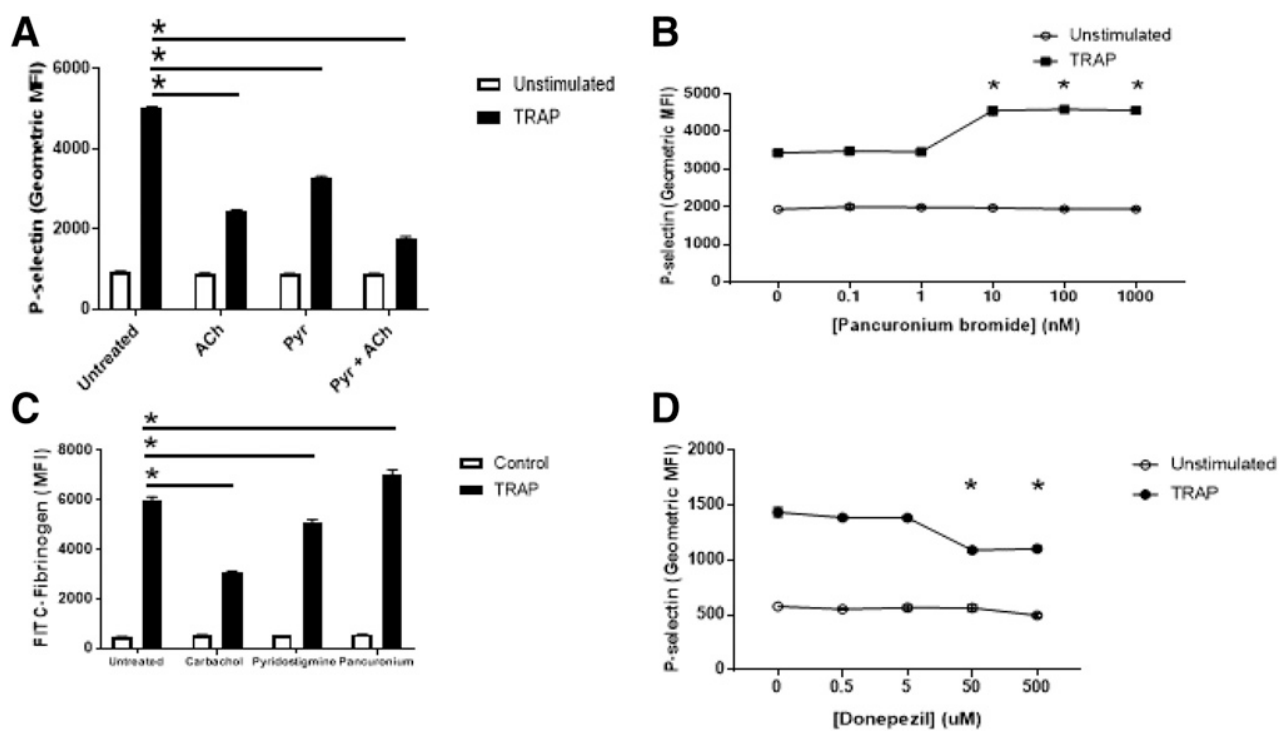

Fig. 2. Endogenous acetylcholine inhibits platelet activation. (A) Pyridostigmine inhibition of AChE permits endogenous acetylcholine inhibition of activation of human platelets. Isolated human platelets were treated with $100 \mu \mathrm{M}$ pyridostigmine or $100 \mu \mathrm{M}$ pyridostigmine and $100 \mu \mathrm{M}$ ACh, stimulated with $10 \mu \mathrm{M}$ TRAP, and then analyzed for P-selectin using flow cytometry $\left(n=4 \pm\right.$ S.D., ${ }^{*} P<0.05$ for TRAP vs. TRAP + pyridostigmine/ACh). (B) Pancuronium antagonism of acetylcholine receptor blocks endogenous acetylcholine inhibition of human platelets. Isolated human platelets were treated with pancuronium and then stimulated with $10 \mu \mathrm{M}$ TRAP and analyzed for P-selectin using flow cytometry $\left(n=4 \pm \mathrm{S}\right.$.D., ${ }^{*} P<0.05$ for TRAP vs. TRAP + pancuronium). (C) Endogenous ACh inhibits GPIIbIIIa conformational changes. Platelets were isolated and treated with $10 \mathrm{nM}$ carbachol, $100 \mu \mathrm{M}$ pyridostigmine, or $100 \mathrm{nM}$ pancuronium bromide and analyzed for FITC-fibrinogen binding to measure GPIIbIIIa activation $(n=4 \pm$ S.D., $* P<0.05$ for TRAP vs. TRAP + indicated compound). (D) Donepezil inhibition of AChE permits endogenous acetylcholine inhibition of activation of human platelets. Isolated human platelets were treated with donepezil hydrochloride and then stimulated with $10 \mu \mathrm{M}$ TRAP and analyzed for P-selectin using flow cytometry $(n=4 \pm$ S.D. $* P<0.05$ for TRAP vs. TRAP + donepezil).

found that L-NAME inhibits the effects of acetylcholine on platelets in a dose-dependent manner (Fig. 3C). Since calcium signaling can regulate NOS activation, we explored a calcium signaling pathway in platelets. First, carbachol increases intracellular calcium levels in platelets (Fig. 3D). Second, the calcium chelator BAPTA blocks the ability of carbachol to inhibit platelets (Fig. 3E). Finally, calmodulin is important for acetylcholine inhibition of platelet activation (Fig. 3F). Taken together, our data suggest that NO mediates acetylcholine inhibition of platelets via a calcium-calmodulin-dependent mechanism.

\section{Discussion}

The major finding of our study is that acetylcholine inhibits platelet activation. Acetylcholine signals through the AChR, increasing NO levels and inhibiting platelet activation. Acetylcholine inhibits activation of platelets from humans by $>15 \%$. Taken together, our results suggest that $\mathrm{AChR}$ activation is a potential endogenous inhibitory pathway that prevents platelet activation.

Two types of AChRs have been described: muscarinic, which are G-protein-coupled receptors, and nicotinic, which are ligand gated ion channels (Itier and Bertrand, 2001; Beker et al., 2003). Nicotinic AChRs are composed of five subunits in different combinations, including $\alpha, \beta, \delta, \varepsilon$, and $\gamma$ subunits (Mishina et al., 1986; Unwin, 2005; Morales-Perez et al., 2016). The precise nature of the AChR in human platelets is not yet defined. Further research is needed to identify the subtypes of acetylcholine receptor and their various functions on platelets.

We have shown that NO mediates acetylcholine inhibition of platelets. Others have demonstrated that platelets express
NOS3 and synthesize NO (Radomski et al., 1990a,b; Sase and Michel, 1995). Prior work has shown that NO inhibits platelet adhesion, activation, and aggregation (Radomski et al., 1987a,b,c; Freedman et al., 1999; Gkaliagkousi et al., 2007). For example, we showed that NO inhibits platelet exocytosis (Matsushita et al., 2003). Others have shown that activators of NO can inhibit platelet function (Doni et al., 1991; Liu et al., 2015). Our work extends these prior studies and shows that calcium-calmodulin signaling, and NOS activity, mediates acetylcholine inhibition of platelet activation. Our work also suggests that diseases or drugs that change NO production may affect platelet activation.

Acetylcholine inhibits activation of platelets by multiple agonists (Fig. 1). Although both PAR1 and P2Y12 are GPCR, they signal through different intracellular messenger pathways (Jin et al., 1998; Boeynaems et al., 2005; Ramachandran et al., 2017; Sanchez Centellas et al., 2017). Convulxin signals through glycoprotein IV (Marlas et al., 1983; Niedergang et al., 2000). Although these pathways ultimately converge to stimulate platelet activation, as measured by conformational changes in GPIIbIIIa, the prior signaling events are different and might be differentially susceptible to NO. Some clinical drugs take advantage of pathway specificity for platelet activation. For example, ticagrelor inhibits platelet activation by inhibiting ADP signaling through the P2Y12 receptor but not through other receptors (Goel, 2013; Patel et al., 2013; von Kugelgen, 2017).

We found that acetylcholine inhibits platelet activation in vitro by about $15 \%$ (Fig. 1B). Carbachol, an analog of acetylcholine, has a much stronger effect on platelet activation, inhibiting P-selectin translocation by $>90 \%$ (Fig. 1A). This is likely due to poor hydrolysis of carbachol by AChE or 
A

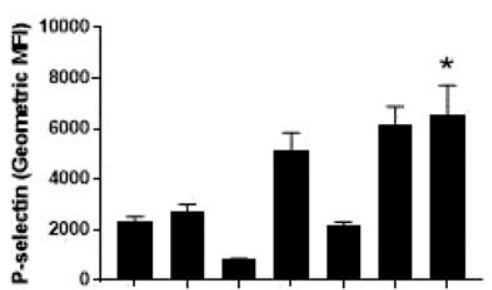

Carbachol L-NAME TRAP

C

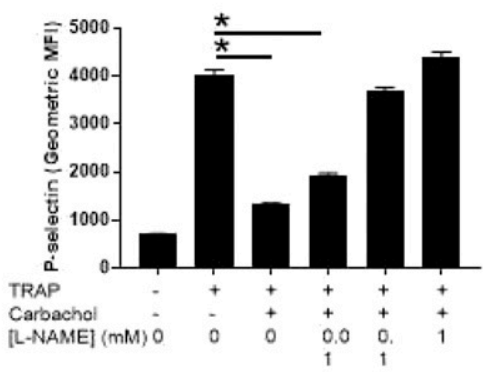

E

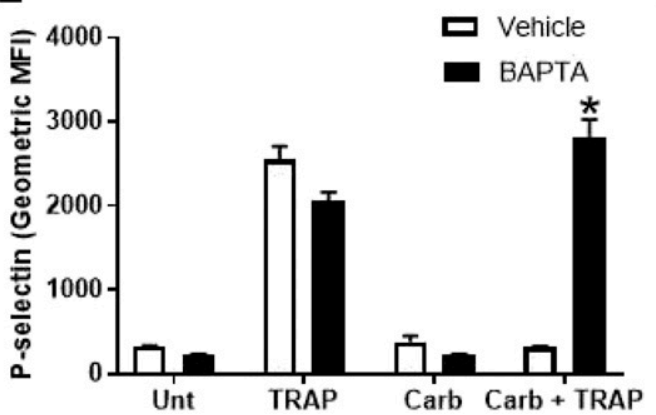

B
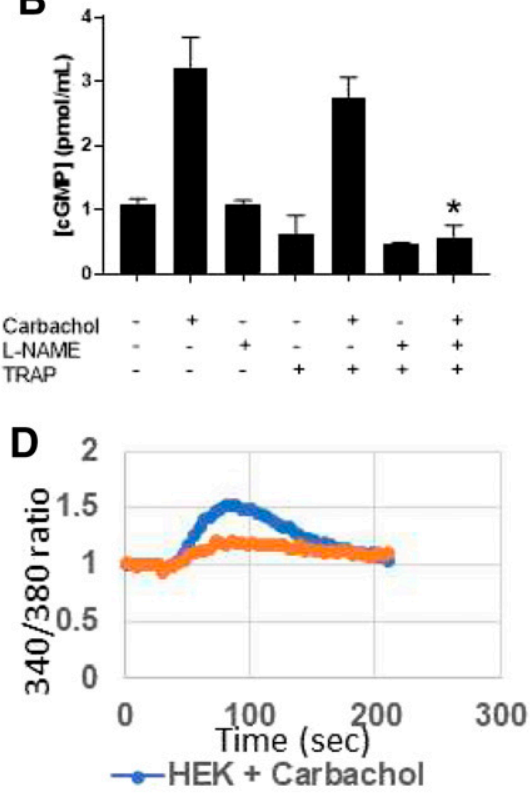

Platelets + Carbachol

$\mathbf{F}$

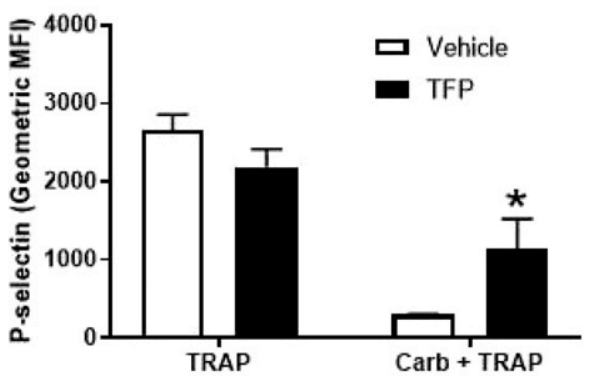

Fig. 3. Nitric oxide mediates Ach inhibition of platelet activation. (A) NOS mediates carbachol inhibition of platelet activation. Isolated human platelets were treated with PBS, carbachol, L-NAME, or L-NAME + carbachol, stimulated with $10 \mu \mathrm{M}$ TRAP, and then analyzed for P-selectin using flow cytometry $\left(n=4 \pm\right.$ S.D., ${ }^{*} P<0.05$ for TRAP + carbachol vs. TRAP + carbachol + L-NAME). (B) NOS mediates carbachol-induced production of cGMP. Isolated human platelets were treated as described, and cGMP content was measured using a commercial kit $(n=4 \pm$ S.D., $* P<0.05$ for TRAP- $6+$ carbachol vs. TRAP + carbachol + L-NAME) (C) L-NAME reversal of carbachol-mediated platelet inhibition is dose-dependent. Platelets were isolated as above and treated with $10 \mathrm{nM}$ carbachol; $1,0.1$, or $0.01 \mathrm{mM} \mathrm{L}$ NAME, and then stimulated with TRAP and analyzed for surface expression of P-selectin. $(n=4 \pm$ S.D., $* P<0.05$ for TRAP + carbachol vs. TRAP + carbachol + indicated concentration of L-NAME). (D) Carbachol elevates intracellular calcium. Platelets or HEK293 cells were loaded with Fura-2 AM, treated with carbachol, and analyzed for calcium flux. (E) Calcium mediates the inhibitory effect of carbachol. Isolated human platelets were treated with BAPTA and then carbachol and then stimulated with TRAP and analyzed for surface expression of p-selectin $(n=4, * P<0.05$ for carbachol + TRAP vs. carbachol + TRAP + BAPTA). (F) Calmodulin activity is required for the inhibitory effect of carbachol. Platelets were treated with trifluoperazine (TFP) and then carbachol and then stimulated with TRAP and analyzed for surface expression of $\mathrm{P}$-selectin $(* P<0.05$ for TRAP + carbachol vs. TRAP + carbachol + TFP). butyrylcholinesterase. Thus, exogenous agonists like carbachol have a powerful effect on platelet activation, but endogenous agonists such as acetylcholine have a more modest inhibitory effect on platelet activation, suggesting a role for endogenous acetylcholine as a novel mechanism to limit aberrant platelet activation.

Our work extends prior research on cholinergic signaling in platelets. Others have shown that agonists of AChR increase human platelet activation ex vivo as measured by GPIIbIIIa conformational changes and by aggregation induced by ADP (Schedel et al., 2011). We show that acetylcholine itself inhibits platelet degranulation (Fig. 1B), and PNU-282987 inhibits P-selectin externalization and inhibits GPIIBIIIA activation (Fig. 3, G-H). This finding confirms our hypothesis that acetylcholine signaling inhibits PAR-1- induced platelet activation. The difference between our work and that of Schedel et al. can potentially be explained by the choice of agonist. Supporting both our studies and hypothesis, others have shown that platelets from mice lacking Chrna 7 have increased aggregation when stimulated by ADP ex vivo (Kooijman et al., 2015).

Our study has several limitations that suggest future studies. We have not yet defined the composition of the acetylcholine receptor on platelets, and we have not identified the role of all acetylcholine subunits in mediating platelet inhibition. Another limitation is that we have indirect evidence that platelets store acetylcholine in their granules since AChE inhibitors boost platelet inhibition, but we have not directly measured acetylcholine inside platelet granules.

Our studies have pharmacologic relevance to humans. We show that donepezil inhibits platelet activation ex vivo at a concentration between 5 and $50 \mu \mathrm{M}$ (Fig. 2D). This matches the concentration of donepezil of $47 \mu \mathrm{M}$ in the serum of humans taking donepezil as a treatment of Alzheimer disease (Hefner et al., 2015). Reports in the literature suggest that drugs targeting the acetylcholine signaling pathway have modest effects on hemostasis; for example, donepezil increases bruising by about $2 \%$ more than does placebo (Birks, 2006). Another recent trial showed a benefit of $\mathrm{AChE}$ inhibitors for reducing the incidence of acute coronary syndrome in patients with dementia by $17 \%$ (Wu et al., 2015). Dementia patients frequently have comorbidities such as diabetes with an elevated risk of thrombosis, so giving these patients more refined and targeted AChE inhibitors may be clinically useful. Our data support our proposal that drugs that target AChE can promote bleeding in humans and may explain why donepezil is associated with hemostatic abnormalities in humans. 
Our study also has therapeutic implications for the management of thrombosis. Our data suggest that drugs targeting acetylcholine receptor subunits might inhibit thrombosis. Furthermore, our data suggest that drugs increasing acetylcholine signaling will increase the risk of bleeding and bruising in patients.

\section{Acknowledgments}

We thank Leisha Machin, Gary Vincelli, Jackie Stephens, and Jackie Velasquez for technical and administrative support during this project.

\section{Authorship Contributions}

Participated in research design: Bennett, Morrell, Cameron, Lowenstein

Performed data analysis: Bennett, Schmidt

Wrote or contributed to the writing of the manuscript: Bennett, Lowenstein, Morrell, Cameron

\section{References}

Beker F, Weber M, Fink RH, and Adams DJ (2003) Muscarinic and nicotinic ACh receptor activation differentially mobilize $\mathrm{Ca} 2+$ in rat intracardiac ganglion neurons. J Neurophysiol 90:1956-1964

Birks J (2006) Cholinesterase inhibitors for Alzheimer's disease. Cochrane Database Syst Rev (1):CD005593.

Boeynaems JM, Communi D, Gonzalez NS, and Robaye B (2005) Overview of the P2 receptors. Semin Thromb Hemost 31:139-149.

Cameron SJ, Ture SK, Mickelsen D, Chakrabarti E, Modjeski KL, McNitt S, Seaberry M, Field DJ, Le NT, Abe J, et al. (2015) Platelet extracellular regulated protein kinase 5 is a redox switch and triggers maladaptive platelet responses and myocardial infarct expansion. Circulation 132:47-58.

Cholongitas E, Pipili C, and Dasenaki M (2006) Recurrence of upper gastrointestinal bleeding after donepezil administration. Alzheimer Dis Assoc Disord 20:326.

Coughlin SR (2005) Protease-activated receptors in hemostasis, thrombosis and vascular biology. $J$ Thromb Haemost 3:1800-1814.

Doni MG, Alexandre A, Padoin E, Bertoncello S, and Deana R (1991) Nitrovasodilators and cGMP inhibit human platelet activation. Cardioscience 2:161-165.

Freedman JE, Sauter R, Battinelli EM, Ault K, Knowles C, Huang PL, and Loscalzo J (1999) Deficient platelet-derived nitric oxide and enhanced hemostasis in mice lacking the NOSIII gene. Circ Res 84:1416-1421.

Gareri P, Gallelli L, Ferreri Ibbadu G, Lacava R, Russo E, and De Sarro G (2005) Melaena following use of the cholinesterase inhibitor rivastigmine. Clin Drug Investig 25:215-217.

Ghoshal K and Bhattacharyya M (2014) Overview of platelet physiology: its hemostatic and nonhemostatic role in disease pathogenesis. Sci World J 2014:781857.

Gkaliagkousi E, Ritter J, and Ferro A (2007) Platelet-derived nitric oxide signaling and regulation. Circ Res 101:654-662.

Goel D (2013) Ticagrelor: the first approved reversible oral antiplatelet agent. Int $J$ Appl Basic Med Res 3:19-21.

Hechler B, Léon C, Vial C, Vigne P, Frelin C, Cazenave JP, and Gachet C (1998) The $\mathrm{P} 2 \mathrm{Y} 1$ receptor is necessary for adenosine $5^{\prime}$-diphosphate-induced platelet aggregation. Blood 92:152-159.

Hefner G, Brueckner A, Hiemke C, and Fellgiebel A (2015) Therapeutic drug monitoring for patients with Alzheimer dementia to improve treatment with donepezil. Ther Drug Monit 37:353-361.

Hisada Y, Geddings JE, Ay C, and Mackman N (2015) Venous thrombosis and cancer: from mouse models to clinical trials. J Thromb Haemost 13:1372-1382.

Holly SP and Parise LV (2011) Big science for small cells: systems approaches for platelets. Curr Drug Targets 12:1859-1870.

Ho-Tin-Noé B, Demers M, and Wagner DD (2011) How platelets safeguard vascular integrity. J Thromb Haemost 9 (Suppl 1):56-65.

Itier V and Bertrand D (2001) Neuronal nicotinic receptors: from protein structure to function. FEBS Lett 504:118-125.

Jin J, Daniel JL, and Kunapuli SP (1998) Molecular basis for ADP-induced platelet activation. II. The P2Y1 receptor mediates ADP-induced intracellular calcium mobilization and shape change in platelets. J Biol Chem 273:2030-2034.

Jin RC, Voetsch B, and Loscalzo J (2005) Endogenous mechanisms of inhibition of platelet function. Microcirculation 12:247-258.

Joshi S and Whiteheart SW (2017) The nuts and bolts of the platelet release reaction. Platelets 28:129-137.

Kooijman S, Meurs I, van der Stoep M, Habets KL, Lammers B, Berbée JF, Havekes LM, van Eck M, Romijn JA, Korporaal SJ, et al. (2015) Hematopoietic $\alpha 7$ nicotinic acetylcholine receptor deficiency increases inflammation and platelet activation status, but does not agoravate atherosclerosis. J Thromb Haemost 13:126-135.

Liu Y, Luo W, Yang H, Fang W, Xi T, Li Y, and Xiong J (2015) Stimulation of nitric oxide production contributes to the antiplatelet and antithrombotic effect of new peptide pENW (pGlu-Asn-Trp). Thromb Res 136:319-327.

Marlas G, Joseph D, and Huet C (1983) Subunit structure of a potent plateletactivating glycoprotein isolated from the venom of Crotalus durissus cascavella. Biochimie 65:619-628.

Matsushita K, Morrell CN, Cambien B, Yang SX, Yamakuchi M, Bao C, Hara MR, Quick RA, Cao W, O'Rourke B, et al. (2003) Nitric oxide regulates exocytosis by S-nitrosylation of N-ethylmaleimide-sensitive factor. Cell 115:139-150.

Mishina M, Takai T, Imoto K, Noda M, Takahashi T, Numa S, Methfessel C, and Sakmann B (1986) Molecular distinction between fetal and adult forms of muscle acetylcholine receptor. Nature 321:406-411.

Moncada S, Higgs EA, and Vane JR (1977) Human arterial and venous tissues generate prostacyclin (prostaglandin $\mathrm{x}$ ), a potent inhibitor of platelet aggregation. Lancet 1:18-20.

Morales-Perez CL, Noviello CM, and Hibbs RE (2016) X-ray structure of the human $\alpha 4 \beta 2$ nicotinic receptor. Nature 538:411-415.

Niedergang F, Alcover A, Knight CG, Farndale RW, Barnes MJ, Francischetti IM, Bon C, and Leduc M (2000) Convulxin binding to platelet receptor GPVI: competition with collagen related peptides. Biochem Biophys Res Commun 273: 246-250

Patel PA, Lane B, and Augoustides JG (2013) Progress in platelet blockers: the target is the P2Y12 receptor. J Cardiothorac Vasc Anesth 27:620-624.

Radomski MW, Palmer RM, and Moncada S (1987a) The anti-aggregating properties of vascular endothelium: interactions between prostacyclin and nitric oxide. Br J Pharmacol 92:639-646.

Radomski MW, Palmer RM, and Moncada S (1987b) Endogenous nitric oxide inhibits human platelet adhesion to vascular endothelium. Lancet 2:1057-1058.

Radomski MW, Palmer RM, and Moncada S (1987c) The role of nitric oxide and cGMP in platelet adhesion to vascular endothelium. Biochem Biophys Res Commun 148:1482-1489.

Radomski MW, Palmer RM, and Moncada S (1990a) Characterization of the L-arginine:nitric oxide pathway in human platelets. $\mathrm{Br}$ J Pharmacol 101:325-328.

Radomski MW, Palmer RM, and Moncada S (1990b) An L-arginine/nitric oxide pathway present in human platelets regulates aggregation. Proc Natl Acad Sci USA 87:5193-5197.

Ramachandran R, Mihara K, Thibeault P, Vanderboor CM, Petri B, Saifeddine M, Bouvier M, and Hollenberg MD (2017) Targeting a proteinase-activated receptor 4 (PAR4) carboxyl terminal motif to regulate platelet function. Mol Pharmacol 91 287-295.

Rogers SL, Doody RS, Mohs RC, and Friedhoff LT; Donepezil Study Group (1998) Donepezil improves cognition and global function in Alzheimer disease: a 15-week, double-blind, placebo-controlled study. Arch Intern Med 158:1021-1031.

Sánchez Centellas D, Gudlur S, Vicente-Carrillo A, Ramström S, and Lindahl TL (2017) A cluster of aspartic residues in the extracellular loop II of PAR 4 is important for thrombin interaction and activation of platelets. Thromb Res 154: 84-92.

Sase K and Michel T (1995) Expression of constitutive endothelial nitric oxide synthase in human blood platelets. Life Sci 57:2049-2055.

Schedel A, Thornton S, Schloss P, Klüter H, and Bugert P (2011) Human platelets express functional alpha7-nicotinic acetylcholine receptors. Arterioscler Thromb Vasc Biol 31:928-934.

Stalker TJ, Welsh JD, and Brass LF (2014) Shaping the platelet response to vascular injury. Curr Opin Hematol 21:410-417.

Tariot PN, Cummings JL, Katz IR, Mintzer J, Perdomo CA, Schwam EM, and Whalen E (2001) A randomized, double-blind, placebo-controlled study of the efficacy and safety of donepezil in patients with Alzheimer's disease in the nursing home setting. J Am Geriatr Soc 49:1590-1599.

Unwin N (2005) Refined structure of the nicotinic acetylcholine receptor at $4 \mathrm{~A}$ resolution. J Mol Biol 346:967-989.

von Kügelgen I (2017) Structure, pharmacology and roles in physiology of the P2Y 12 receptor. Adv Exp Med Biol 1051:123-138.

Wu PH, Lin YT, Hsu PC, Yang YH, Lin TH, and Huang CT (2015) Impact of acetylcholinesterase inhibitors on the occurrence of acute coronary syndrome in patients with dementia. Sci Rep 5:15451.

Zhu Q, Yamakuchi M, Ture S, de la Luz Garcia-Hernandez M, Ko KA, Modjeski KL, LoMonaco MB, Johnson AD, O'Donnell CJ, Takai Y, et al. (2014) Syntaxin-binding protein STXBP5 inhibits endothelial exocytosis and promotes platelet secretion. $J$ Clin Invest 124:4503-4516.

Zuccolo E, Lim D, Kheder DA, Perna A, Catarsi P, Botta L, Rosti V, Riboni L, Sancini G, Tanzi F, et al. (2017) Acetylcholine induces intracellular $\mathrm{Ca}^{2+}$ oscillations and nitric oxide release in mouse brain endothelial cells. Cell Calcium 66:33-47.

Address correspondence to: John Allen Bennett, University of Rochester Medical Center 601 Elmwood Avenue, Box G-1441 Rochester, NY 14642. E-mail: johna_bennett@urmc.rochester.edu 